\title{
A Rare Case of Lingual Necrosis Secondary to Prolonged Endotracheal Intubation
}

\author{
Samran Haider ${ }^{\mathrm{a}, \mathrm{b}}$, Kartik Kumar ${ }^{\mathrm{a}}$, Cassondra Cramer ${ }^{\mathrm{a}}$, Christopher Garcia ${ }^{\mathrm{a}}$, \\ Michelle El-Hosni ${ }^{\mathrm{a}}$, Diane Levine ${ }^{\mathrm{a}}$
}

\begin{abstract}
We present a unique case of partial necrosis and cleft of the tongue caused by an endotracheal tube, and highlight the importance of endotracheal tube positioning in patients requiring prolonged intubation. A 53-year-old woman underwent endotracheal intubation secondary to respiratory failure due to altered mental status caused by alcohol intoxication. After extubation, she complained of tongue pain and was found to have cleft tongue and necrosis secondary to prolonged intubation. On follow-up, the patient's tongue pain improved with oral analgesics and the tongue was well healed on examination. Tongue necrosis due to compression by an endotracheal tube during prolonged intubation is unusual; however, those involved in the care of intubated patients should consider the potential for this complication. This unique case of tongue necrosis highlights the importance of proper endotracheal tube positioning during prolonged intubation.
\end{abstract}

Keywords: Intubation; Necrosis; Tongue; Alcoholic intoxication; Complications; Intratracheal intubation

\section{Introduction}

Oral complications of endotracheal intubation are common and include injury to the teeth, lips, gums and oral mucosa. Most of these injuries result from traumatic insertion of the oral endotracheal tube, but some may occur after initial placement of the tube. While rare, injuries of the tongue due to intubation have been reported as early as 1978 [1]. We report a case of laceration and cleft of the tongue from prolonged use of oral airway.

\footnotetext{
Manuscript accepted for publication August 12, 2016

aUniversity Health Center, 4201 Saint Antoine Street University Health Center, Room 2E, Detroit, MI 48201, USA

${ }^{b}$ Corresponding Author: Samran Haider, University Health Center, 4201 Saint Antoine Street University Health Center, Room 2E, Detroit, MI 48201, USA. Email: shaider@med.wayne.edu
}

doi: http://dx.doi.org/10.14740/jmc2616w

\section{Case Report}

A 53-year-old female with a past medical history significant for alcohol-induced hepatic cirrhosis presented with respiratory failure secondary to alcohol intoxication. She was subsequently successfully intubated atraumatically on the first attempt using a 7.5 cuffed endotracheal tube. The endotracheal tube was secured at $21 \mathrm{~cm}$ at the lip. Post-intubation chest X-ray demonstrated satisfactory placement. She was intubated for a total of 9 days. After extubation, the patient reported tongue pain and difficulty phonating. Intraoral examination revealed a midline cleft on the tongue measuring $3 \mathrm{~cm}$ with necrosis (Figs. 1 and 2). Cranial nerve examination was normal. The tongue pain improved with oral analgesics.

\section{Discussion}

Prolonged intubation, or intubation occurring for more than 4 days [2], is commonly associated with some serious but oftentimes mild complications. One such mild complaint, tongue swelling, is ubiquitous for those undergoing surgical procedures and has previously been reported [3-5]. Tongue swelling has also been seen in patients requiring flexed thoraciccervical positioning during spinal surgeries [6]. Patients may

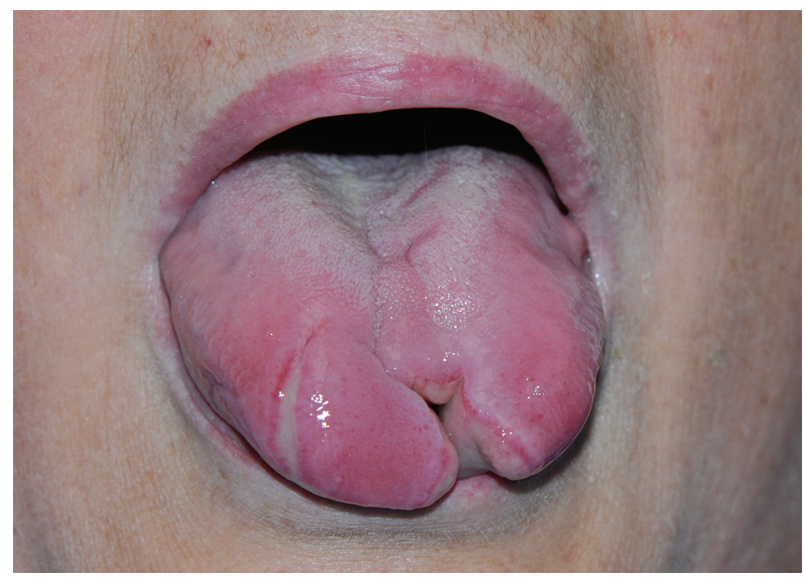

Figure 1. Dorsal view of the tongue showing healing tongue with midline cleft. 


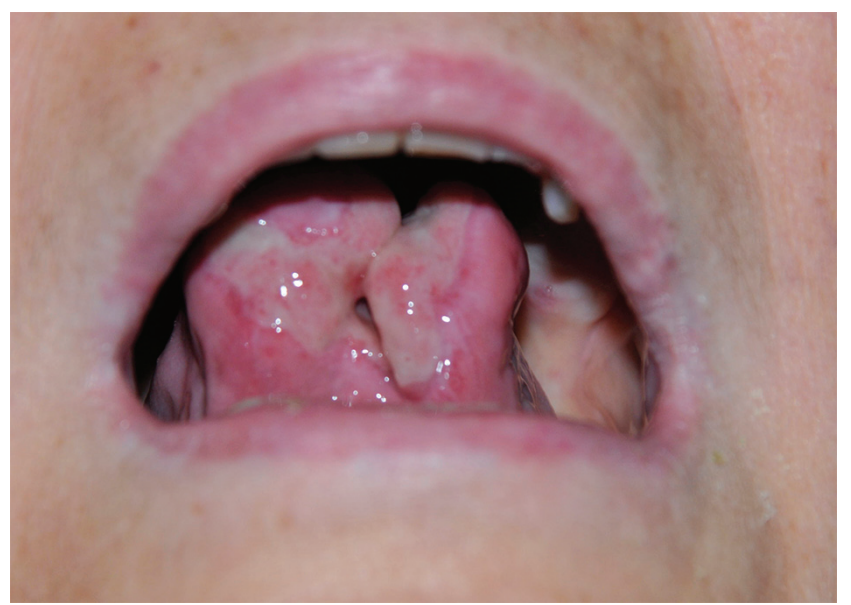

Figure 2. Ventral view of the tongue showing tongue ulceration with midline cleft.

also present with apparent lingual swelling after extubation due to sialadenitis from submandibular duct obstruction by the endotracheal tube or traumatic intubation causing a sublingual hematoma $[7,8]$. Other mild complications of prolonged intubation include difficulty with phonation and dysphagia after extubation [9], while more serious complications include laryngeal injury and upper airway distress requiring advanced airway management $[2,10]$.

Ischemic necrosis of the tongue in intubated patients is rare and previously reported in patients with cardiogenic shock requiring pressor support or those undergoing prolonged neurosurgical or head and neck surgeries [11, 12]. In non-intubated patients, tongue necrosis has been reported with trauma, local vasculitis and rarely with transient ischemic attacks and disseminated intravascular coagulation [13-15]. Tongue necrosis has also been reported following prolonged transesophageal echocardiography probe placement, broadening the situations in which this condition may occur [16].

Factors that contribute to lingual necrosis include local pressure, deep sedation and hemodynamic instability [17]. Our patient required intubation for 9 days for respiratory failure, and she did not undergo any surgical procedure during this time nor did she require pressor support.

Tongue necrosis can result in functional deficits. Healthcare providers should be aware of this potential complication in patients who require prolonged oral intubation. When edema of the tongue is noted, an attempt should be made to change the position of the endotracheal tube or other transoral devices. These simple maneuvers may prevent progression to tissue necrosis and possible morbidity [16].

Tongue necrosis is a rare but important complication of prolonged oral intubation as well as other procedures that may lead to increased intraoral pressure. Regular monitoring may help prevent this morbid complication.

\section{Conflicts of Interest}

None.

\section{Financial Support}

None.

\section{References}

1. Stauffer JL, Petty TL. Cleft tongue and ulceration of hard palate: complications of oral intubation. Chest. 1978;74(3):317-318.

2. Gaynor EB, Greenberg SB. Untoward sequelae of prolonged intubation. Laryngoscope. 1985;95(12):14611467.

3. Rajesh M, Kuriakose S, Sukumar J, Ramdas E. Massive lingual swelling following cleft palate repair. J Anaesthesiol Clin Pharmacol. 2013;29(2):262-263.

4. Saah D, Braverman I, Elidan J, Nageris B. Traumatic macroglossia. Ann Otol Rhinol Laryngol. 1993;102(9):729730 .

5. Miura Y, Mimatsu K, Iwata H. Massive tongue swelling as a complication after spinal surgery. J Spinal Disord. 1996;9(4):339-341.

6. DePasse JM, Palumbo MA, Haque M, Eberson CP, Daniels AH. Complications associated with prone positioning in elective spinal surgery. World J Orthop. 2015;6(3):351359.

7. Huehns TY, Yentis SM, Cumberworth V. Apparent massive tongue swelling. A complication of orotracheal intubation on the Intensive Care Unit. Anaesthesia. 1994;49(5):414-416.

8. McGoldrick KE, Donlon JV. Sublingual hematoma following difficult laryngoscopy. Anesth Analg. 1979;58(4):343-344.

9. Bordon A, Bokhari R, Sperry J, Testa Dt, Feinstein A, Ghaemmaghami V. Swallowing dysfunction after prolonged intubation: analysis of risk factors in trauma patients. Am J Surg. 2011;202(6):679-682; discussion 682673.

10. Deeb ZE, Williams JB, Campbell TE. Early diagnosis and treatment of laryngeal injuries from prolonged intubation in adults. Otolaryngol Head Neck Surg. 1999;120(1):2529.

11. Roman BR, Immerman SB, Morris LG. Ischemic necrosis of the tongue in patients with cardiogenic shock. Laryngoscope. 2010;120(7):1345-1349.

12. Teeple E, Maroon J, Rueger R. Hemimacroglossia and unilateral ischemic necrosis of the tongue in a longduration neurosurgical procedure. Anesthesiology. 1986;64(6):845-846.

13. Goicochea M, Correale J, Bonamico L, Dominguez R, Bagg E, Famulari A, Ameriso S, et al. Tongue necrosis in temporal arteritis. Headache. 2007;47(8):1213-1215.

14. Orita Y, Ogawara T, Yorizane S, Nannba Y, Akagi H, Nishizaki K. Necrosis of the tongue after transient ischemic attack. Oral Surg Oral Med Oral Pathol Oral Radiol Endod. 2000;89(3):316-318.

15. Kamatani T, Yamashita K, Okabayashi T, Maeda H, Toi $\mathrm{M}$, Yamamoto T. Bilateral ischemic necrosis of the tongue 
due to disseminated intravascular coagulation. Int J Oral Maxillofac Surg. 2008;37(8):777-779.

16. Sriram K, Khorasani A, Mbekeani KE, Patel S. Tongue necrosis and cleft after prolonged transesophageal echocardiography probe placement. Anesthesiology. 2006;105(3):635.
17. Nao Okuda, Yumiko Tsunano, Miwa Miyauchi, Hisakazu Kohata, Emiko Nakataki, Taiga Itagaki, Mutsuo Onodera, Hideaki Imanaka. A case of tongue necrosis due to an endotracheal tube. Journal of the Japanese Society of Intensive Care Medicine. 2013;20(2):271272. 